\title{
Numerical Simulation of Turbulent Flow and Heat Transfer in an Anti- Gravity Blind Duct with Tangential Entry Jet
}

\author{
Shyy Woei Chang ${ }^{1, *}$ and Zong-Xian Cai ${ }^{2}$ \\ ${ }^{I}$ Thermal Fluids Laboratory, National Kaohsiung Marine University, No. 142, Haijhuan Road, Nanzih District, Kaohsi- \\ ung City 81143, Taiwan, ROC \\ ${ }^{2}$ Research Student, Department of Marine Engineering, National Kaohsiung Marine University, No. 142, Haijhuan \\ Road, Nanzih District, Kaohsiung City 81143, Taiwan, ROC
}

\begin{abstract}
This numerical study investigates the flow and heat transfer characteristics in a vertical square blind duct with the coolant fed by a tangential entry jet. The detailed Nusselt number $(\mathrm{Nu})$ distributions over the five constituent walls of the blind duct are calculated at duct (jet) Reynolds numbers $R e\left(R e_{j}\right)$ of 5000(20000), 7000(28000) and 10000(40000) using the commercial CFD Star CD code. As an attempt to explore the buoyancy effect on heat transfer performances, three different heat fluxes, which vary the gravitational Grashof numbers $\left(G r_{g}\right)$ at the fixed $R e$, are imposed on each duct wall to vary the buoyancy levels. The jet-induced flow phenomena in the blind duct exhibit various heat transfer impacts on the five duct walls over which the different near-wall flow structures are generated. This is demonstrated by cross-examining the detailed $N u$ distributions and the area-averaged Nusselt number $(\overline{N u})$ over the five duct walls at the tested $R e$ and $G r_{g}$. The cross-plane swirls induced by the tangential entry jet together with the impinging jet flows considerably elevate the Heat Transfer Enhancement (HTE) performances in the blind duct. Within the parametric conditions simulated, the ratios of $\overline{N u}$ to the Dittus-Boelter levels $\left(N u_{\infty}\right)$ over the jet wall, back wall, impingement wall, side wall and end wall are respectively raised to $3-5.7,2.8-5.6,3-5.8,2.7-4.8$ and 3.1-6.1; while the HTE ratios ( $\overline{N u} / N u_{\infty}$ ) over these duct walls consistently decrease as $R e$ increases.
\end{abstract}

Keywords: Turbulent Heat Convection, Blind Duct, Tangential Entry Jet.

\section{INTRODUCTION}

Convective heat transfer in a blind duct has found various industrial applications to attack the closed heat exchange problems, such as the tip cooling of an acetylene welder, the shaker-bore piston cooling scheme, the internal coolant channels in gas turbine blades and the recovery of thermal energy using an open thermosyphon. Depending on the geometrical and thermal boundary conditions imposed, the flow structures in blind ducts, which accordingly characterize their heat transfer performances, can vary to large extents. But these various flow structures in the blind ducts are subject to a physical condition of no net mass flow rate across any cross section. As a result, for a vertical blind duct which is often referred to as the open thermosyphon, the flow structures developed within are generally characterized by multiple duct-wise coherent vortical cells [1]. By way of varying the tilt angle from vertical to horizontal orientation, the multi-vortical cells in a vertical blind duct can transit to the counter directional hot-return and cold-entry streams and eventually yield to the different forms of multi-cellar vortices in a horizontal blind duct [2-6]. Another geometrical parameter which has profound influences on the thermal fluid flows in a blind duct is the duct length (L) to width (W)

*Address correspondence to this author at the Thermal Fluids Laboratory, National Kaohsiung Marine University, No. 142, Haijhuan Road, Nanzih District, Kaohsiung City 81143, Taiwan, ROC; Tel: +886 7 8100888-5216; Fax: + 88675712219 ; E-mail: swchang@mail.nkmu.edu.tw ratio. As $\mathrm{L} / \mathrm{W}$ increases, the number of vortices in a blind duct is generally increased but the strength of these vortices near the blind end is considerably weakened. Within the flow region near the blind end, the dominant thermal transfer process is buoyancy advection [1] which is sensitive to the duct orientation. When the wall temperature distributions are asymmetric over the blind duct, the vortices developed near the blind end can be three dimensional [1]. In the extreme case, the hot sealed end of a vertical blind duct is above its cold open end so that the duct-wise fluid temperature gradients are in the opposite direction to gravity. This so-called anti-gravity blind duct flow features a worse case heat transfer scenario as the regional fluency of the coolant flow near the sealed end is undermined by the gravity-driven buoyant advection. With anti-gravity conditions, the weakened ductwise fluid inertia as a result of viscous dispassion and the adverse pressure gradients which have built up near the closed end of the blind duct interact together to cause a flow transition from turbulent to a laminar regime as the coolant flows from the open end towards its close end [7]. Unlike the Poiseuille ducted flow which is driven by the pressure gradients through a duct, the flow structures in a blind duct are either developed as multi-cellar vortices or stratified hot/cold streams so that the overall $\mathrm{Nu}$ levels for long blind ducts with $\mathrm{L} / \mathrm{W} \geq 4$ are considerably less than the $N u_{\infty}$ references obtained at the through flow conditions. Moreover, the strong duct-wise flow momentum for a Poiseuille ducted through flow can usually interact with the passive Heat Transfer Enhancement (THE) devices, such as surface ribs 
and twisted tapes, to produce considerable HTE impacts. For a blind duct, the HTE impacts of these passive devices are considerably suppressed from the Poiseuille-flow counterparts. Only marginal HTE impacts are generated in an antigravity blind duct which is enhanced by twisted tape insert [8], surface ribs [9] or channel inclination [10]. The limited HTE performances attributed from these HTE devices in a blind duct are mainly caused by the weak flow momentum in the duct-wise direction. For improving the heat transfer performances in a blind duct with piston cooling applications, the shaker-jet cooling scheme with the coolant entering the blind duct in a form of free jet from the open end is developed. The improved coolant penetration into the blind duct as well as the augmented turbulent activities tripped by the shear layer, which encapsulates the cold entry jet by the enveloping hot-return stream, considerably elevate the overall $N u$ from those in the similar blind ducts [11]. In an attempt to further increase the $N u$ levels in a blind duct, a jet-swirl cooling scheme, which feeds the coolant into the blind duct near its closed end by way of tangential jet injection, triggers several HTE mechanisms, including jet impingement, turbulence augmentation and swirl flows. In addition, the transport and mixing of the fluids in such a blind duct can also be considerably improved. This numerical study examines the flow structures and the corresponding heat transfer performances for a vertical anti-gravity blind square duct with the coolant entering the duct in the form of horizontal tangential jet. The jet-induced flow phenomena in the blind duct along with the wall-to-fluid heat transfer properties over five constituent duct walls are cross examined to disclose the thermal physics relevant to the HTE performances generated by the jet-swirl cooling scheme.

\section{NUMERICAL TREATMENTS}

The system geometry investigated by this study has the particular cooling application to the piston of an advanced heavy duty marine propulsive diesel engine, Fig. 1(a). The coolant is forced convective and directed from the concentric annulus in the piston rod to each vertical blind bore in the form of a lateral tangential jet, Fig. 1(a). The conductive heat flux from the piston material is transferred to the coolant in each blind bore and transported out of the piston by the flow through the coolant passage in the piston rod. The present coordinate system and the flow configuration of the square blind duct with a tangential entry jet in the direction normal to the duct wall are depicted by Fig. 1(b). The five constituent duct walls, namely jet wall, back wall, impingement wall, side wall and end wall are indicated in Fig. 1(b). The duct length (L) to width (W) ratio is $112 \mathrm{~mm} / 28 \mathrm{~mm}$. The horizontal entry jet is generated by feeding the coolant through a square sectioned orifice with a width of $7 \mathrm{~mm}$. The distance between the jet center and the end wall is $35 \mathrm{~mm}$. The hydrodynamic diameters of the blind duct $(d)$ and the jet $\left(d_{j}\right)$ are 28 and $7 \mathrm{~mm}$ respectively. The dimensionless parameters, namely $N u, R e$ and $G r_{g}$, are evaluated using $d$ as the characteristic length; while $R e_{j}$ based on $d_{j}$ is also determined to define the flow entry condition. Over each of the five constituent duct walls, the uniform heat flux is imposed. These pre-defined heat fluxes can be systematically increased to elevate $G r_{g}$ in order to examine the buoyancy effect on heat transfer. This blind duct, which features the antigravity condition, is cooled by a single phase water flow of $P r=5.31$ with the uniform distributions of fluid temperature and velocities over the jet entry plane. The test coolant is modeled as a Newtonian fluid. Fluid properties are calculated at the local fluid temperatures which are collected from each iteration process. This model is a steady representation of the problem. Equations (1)-(5) are the turbulent momentum and energy equations with the aid of gravity-driven buoyancy effect, which are solved by using the commercial finite difference code STAR CD [12]. (a) Jet-swirl piston cooling system

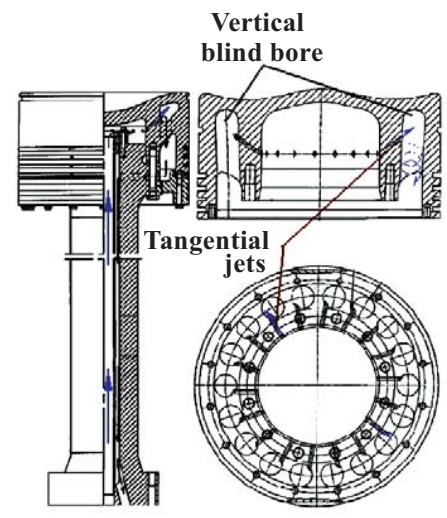

(b) Flow configuration

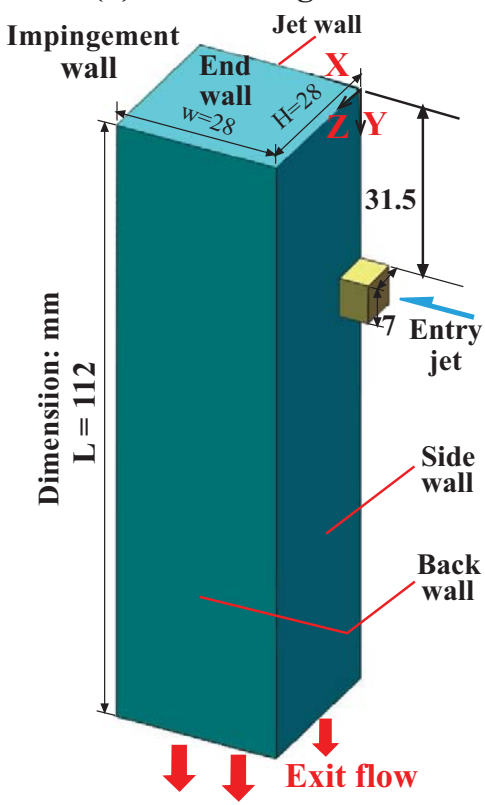

(c) Mesh structure

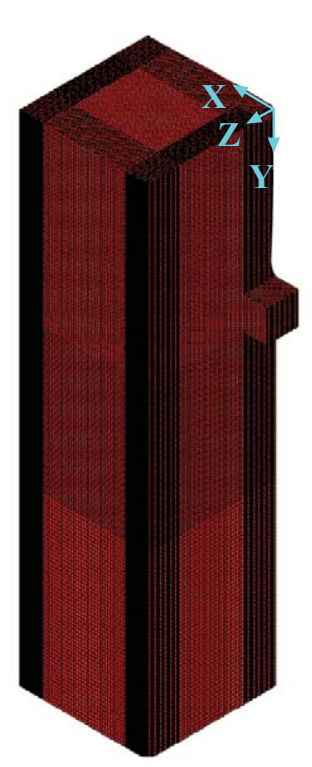

Fig. (1). (a) jet-swirl piston cooling scheme (b) flow configuration (c) mesh structure. 
$\bar{U}_{j} \frac{\partial u_{i}}{\partial x_{j}}=-\frac{1}{\rho} \frac{\partial p}{\partial x_{i}}+\frac{1}{\rho} \frac{\partial \tau_{j i}}{\partial x_{j}}-g \beta\left(T-T_{\infty}\right)$

where

$$
\begin{aligned}
& \tau_{i j}=\left[\mu\left(\frac{\partial u_{i}}{\partial x_{j}}+\frac{\partial u_{j}}{\partial x_{i}}\right)+\rho\left(\overline{u_{i} u_{j}}-\bar{U}_{i} u_{j}-u_{i} u_{j}\right)\right] \\
& \rho \bar{U}_{j} \frac{\partial k}{\partial x_{j}}=\frac{\partial}{\partial x_{j}}\left[-\overline{p u_{j}}-\frac{1}{2} \rho \overline{u_{i} u_{i} u_{j}}+\mu \frac{\partial k}{\partial x_{j}}\right]-\rho \overline{u_{i} u_{j}} \frac{\partial \bar{U}_{i}}{\partial x_{j}}-2 \mu \overline{S_{i j} S_{i j}}
\end{aligned}
$$

where

$$
\begin{aligned}
& S_{i j}=\frac{1}{2}\left(\frac{\partial u_{i}}{\partial x_{j}}+\frac{\partial u_{j}}{\partial x_{i}}\right) \\
& k=0.5\left(\overline{u_{i} u_{i}}\right)
\end{aligned}
$$

To close equations (1)-(5) which involve turbulent quantities, several turbulence models can be selected in the STAR CD running routine. This control-volume based STAR CD code implements the SIMPE algorithm with pressure corrections to solve the Reynolds averaged Navier-Stokes equations as well as all the transport equations involving turbulent quantities. With the present structured grids as seen in Fig. 1(c), the lower order Upwind Differencing (UD) scheme is used to determine the spatial convective flux for all flow equations solved. These coupled linear systems of the flow equations are solved using the conjugate gradient method. Nonslip boundary conditions are set at all the constituent duct walls. With several test runs using the standard $k-\varepsilon$ and $k-\omega$ models, the maximum discrepancies in the fluid velocities obtained from these two turbulence models are less than $\pm 10 \%$. As the turbulent activities are expected as nonhomogeneous, the $k-\omega$ model is adopted to solve the turbulent quantities in order to close the additional terms in the time-averaged momentum and energy equations for turbulent flows [12]. The two sets of additional transport equations for turbulent kinetic energy $(k)$ and specific dissipation rate $(\omega)$ are respectively depicted by equations (6) and (7).

$$
\begin{aligned}
& \frac{\partial}{\partial x_{j}}\left[\rho u_{j} k-\left(\mu+\frac{\mu_{t}}{\sigma_{k}^{\omega}}\right) \frac{\partial k}{\partial x_{j}}\right]=\mu_{t} P-\rho \beta^{*} k \omega+\mu_{t} P_{B} \\
& -\frac{\partial}{\partial x_{j}}\left[\rho u_{j} \omega-\left(\mu+\frac{\mu_{t}}{\sigma_{\omega}^{\omega}}\right) \frac{\partial \omega}{\partial x_{j}}\right]=\alpha \frac{\omega}{k} \mu_{t} P- \\
& \rho \beta \omega^{2}-\rho s S_{\omega}-C_{\varepsilon 3} \mu_{t} P_{B} C_{\mu} \omega
\end{aligned}
$$

where the mean strain $S_{k i}=\frac{\partial u_{k}}{\partial x_{i}}+\frac{\partial u_{i}}{\partial x_{k}}$ and the mean vorticity tensor $\Omega_{i, j}=\frac{\partial u_{i}}{\partial x_{j}}-\frac{\partial u_{j}}{\partial x_{i}}$ are determined from the strain rates; and

$$
\begin{aligned}
& \beta=\beta_{0} f_{\beta}, \beta^{*}=\beta_{0} * f_{\beta^{*}} \\
& f_{\beta^{*}}=1\left(\chi_{k} \leq 0\right), f_{\beta^{*}}=\frac{1+680 \chi_{k}^{2}}{1+400 \chi_{k}^{2}}\left(\chi_{k}>0\right), f_{\beta}= \\
& \left(1+70 \chi_{\omega}\right) /\left(1+80 \chi_{\omega}\right), \chi_{k}=\frac{1}{\omega^{3}} \frac{\partial k}{\partial x_{j}} \frac{\partial \omega}{\partial x_{j}}
\end{aligned}
$$

$$
P_{B} \equiv-\frac{g_{i}}{\sigma_{h}} \frac{1}{\rho} \frac{\partial \rho}{\partial x_{i}}
$$

The coefficients in the $k-\omega$ model are $\alpha=0.52, \beta_{0}=0.072$, $\beta_{0}{ }^{*}=0.09, \mathrm{C}_{\varepsilon 3}=1.44, \mathrm{C}_{\mu}=0.09, \sigma_{k}^{\omega}=\sigma_{\omega}^{\omega}=2, \sigma_{h}=0.9$. The turbulent viscosity $\left(\mu_{t}\right)$ is defined as $\rho k / \omega$.

The present structure mesh is generated by using an interactive grid generation code GRIDGEN. As shown in Fig. $\mathbf{1}(\mathbf{c})$, the meshes are refined in the near wall regions where the larger velocity gradients are expected. Each element has 8 nodes with the maximum grid spacing of 0.05 jet diameter. The convergence criterion was pre-set in the STAR CD code as such that the normalized residuals for the mass and momentum equations were smaller than $10^{-4}$, and the residual of the energy equation was less than $10^{-4}$. To ensure the mesh independency for the present study, several mesh refinement tests are performed. The monitored physical quantity for the mesh independency is the local fluid velocity. The criterion for grid independency is selected as $\left|\vec{v}_{i}\right|-\left|\vec{v}_{i-1}\right|||\left|\vec{v}_{i}\right| \leq 0.05$, in which $|\vec{v}|$ is the absolute local fluid velocity obtained at the $i^{\text {th }}$ mesh iteration index. The grids are more refined when the $i$ index is increased. The result of the mesh independency test is depicted by Fig. (2) in which the X-wise distributions of local fluid absolute velocities $(|\vec{v}|)$ along $\mathrm{Z} / \mathrm{H}=0.99$ (near the back wall) and $\mathrm{Y} / \mathrm{d}=2$ (middle section of the blind duct) axes obtained from three different meshes at $R e=$ (a) 7000 , (b) 10000 are compared. The comparative results indicate that the grids with 2700000 and 3700000 elements are in close agreements which satisfy the convergence criterion for mesh independency, Fig. (2). The comparative results revealed by Fig. (2) are consistently followed for all the $R e$ examined by this study. The grid system with 2700000 elements is therefore selected to perform the present numerical simulations.

This particular cooling application involves mixed convection with complex buoyancy effects on the heat transfer performance. Several previous studies have been conducted on the implementation of various turbulence models to resolve the mixed convection phenomena [13-14]. The complexities are mostly associated with the near-wall flow interaction between the velocity field and the turbulence production for buoyancy-aided and buoyancy-opposed flows. The simulations of buoyancy-aided mixed convection in the vertical tubes using the low-Reynolds-number $k$ - $\varepsilon$ turbulence model [15] found acceptable agreement with the experimental data [16]. In the recent assessment of the performance of a variety of turbulence models in simulating the mixed convection in vertical tubes, which particularly compared the results from the RANS-based models and the DNS results [14], the dominant mechanism that caused laminarization and deterioration of heart transfer was consistently found as the indirect influence of the buoyancy force on the turbulence. These previous results [13-16] confirmed that the RANS approaches are suitable to attack the mixed convection problems. As an illustrative example to justify the selection of the turbulence model for this study, three sets of wall 
(a) $Z / H=0.99, Y / d=2, R e=7000$

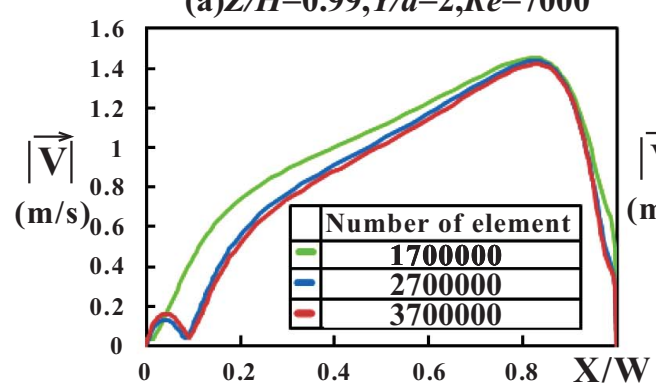

(b) $Z / H=0.99, Y / d=2, R e=10000$

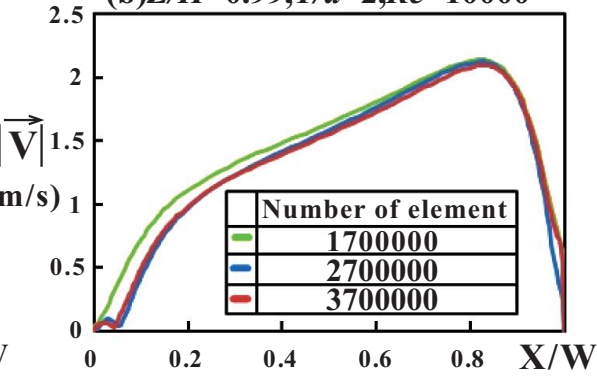

Fig. (2). $\mathrm{Y}$-wise velocities distributions obtained by different meshes at $\mathrm{Z} / \mathrm{H}=0.99, \mathrm{Y} / d=2$ with $R e=$ (a) 7000, (b) 10000 .

temperature $\left(T_{w}\right)$ distributions on the jet and back walls obtained from (a) RANS $k-\omega$ (b) RANS $k-\varepsilon$ (c) Reynolds Stress Model (RSM) models are compared with (d) experimental measurements generated by this research project, Fig. (3). As the exit end of the experimental blind duct is connected with a plenum chamber to emulate the sudden expansion effect, the high $T_{w}$ regions adjacent to the flow exit shown by Fig. 3(d) are not observed in Figs. 3(a)-(c) due to the exclusion of the sudden expansion exit for the present numerical model. Among the three sets of comparative results depicted by Figs. 3(a)-(c), the area-averaged wall temperature $\left(\bar{T}_{w}\right)$ as well as the pattern of $T_{w}$ distribution predicted by RANS $k-\omega$ turbulence model are in the closer agreement with the experimental results showed by Fig. 3(d). Such comparative results are consistently found for all the simulating conditions. Therefore the RANS approach using the $k-\omega$ turbulence model is selected to solve the convective flow phenomena in the vertical blind duct with a tangential entry jet.

\section{RESULTS AND DISCUSSION}

The flow velocity vector plots at $R e=$ (a) 5000 (b) 7000 (c) 10000 over the selected Z-Y, X-Y and X-Z planes are collected in Fig. (4). These sectional velocity plots assist to visualize the complex flow structures developed in the blind duct with a tangential lateral jet attached on the jet wall. As compared in Figs. 4(a)-4(c), the increase of Re elevates the local fluid velocities with only marginal variations in the scales of the vortical cells over each sectional plane, Fig. (4). When the $7 \mathrm{~mm} d_{j}$ tangent lateral jet enters the $28 \mathrm{~mm} d$ blind duct in the direction aligned with $\mathrm{Y} / \mathrm{L}=0.32$ axis, the strong swirling circulations are induced on the $\mathrm{X}-\mathrm{Z}$ planes downstream the $X-Z$ jet plane at $Y / L=0.32$, Fig. (4). Over the impingement wall $(\mathrm{X} / \mathrm{W}=1)$ after the jet impingement, the velocity distributions on the $\mathrm{Z} / \mathrm{Y}$ plane at $\mathrm{X} / \mathrm{W}=0.99$ clearly indicate the trajectories of the impacted and redirected flow which generates the upper surging flows to create the three dimensional multi-cellar vortices beneath the blind wall. These vortical structures underneath the blind wall, which are induced by the redirected upward flow, can be visualized from the velocity plots on the $\mathrm{Z}-\mathrm{Y}$ plane at $\mathrm{X} / \mathrm{W}=0.5$ and over the $\mathrm{X} / \mathrm{Z}$ plane at $\mathrm{Y} / \mathrm{L}=0.003$, Fig. (4). As shown by these plots, the velocity vectors on the $X-Z$ plane near the blind wall $(\mathrm{Y} / \mathrm{L}=0.003)$ depict several coherent vortices which are triggered by the skewed injecting stream emanating from the upper left corner of the blind duct. These vor-

\section{$R e=7000, G r_{g}=1941000$ (jet wall) 3348000 (backwall)}

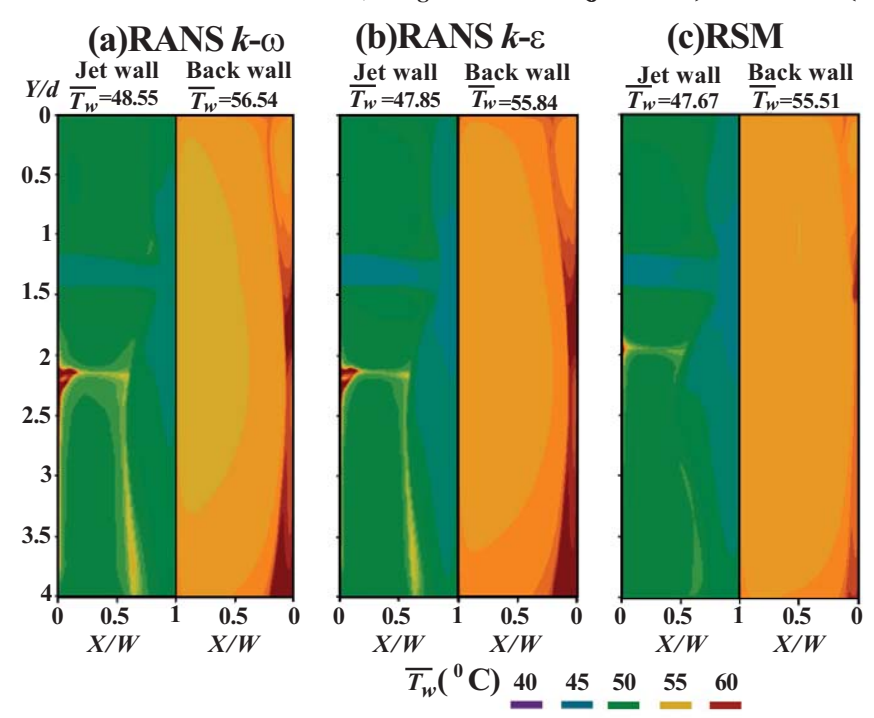

(d) $\begin{gathered}\text { Experimental } \\ \text { measurements }\end{gathered}$

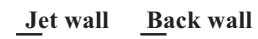
$\overline{T_{w}}=48.5 \quad \overline{T_{w}}=58.96$

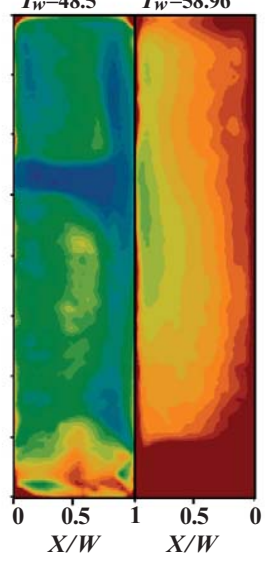

Fig. (3). Comparison of $T_{w}$ distributions over the jet and back walls using (a) RANS $k$ - $\omega$ (b) RANS $k-\varepsilon$ (c) RSM turbulence models (d) experimental measurements at $R e=7000, G r_{g}=1941000$ (jet wall) 3348000 (back wall). 


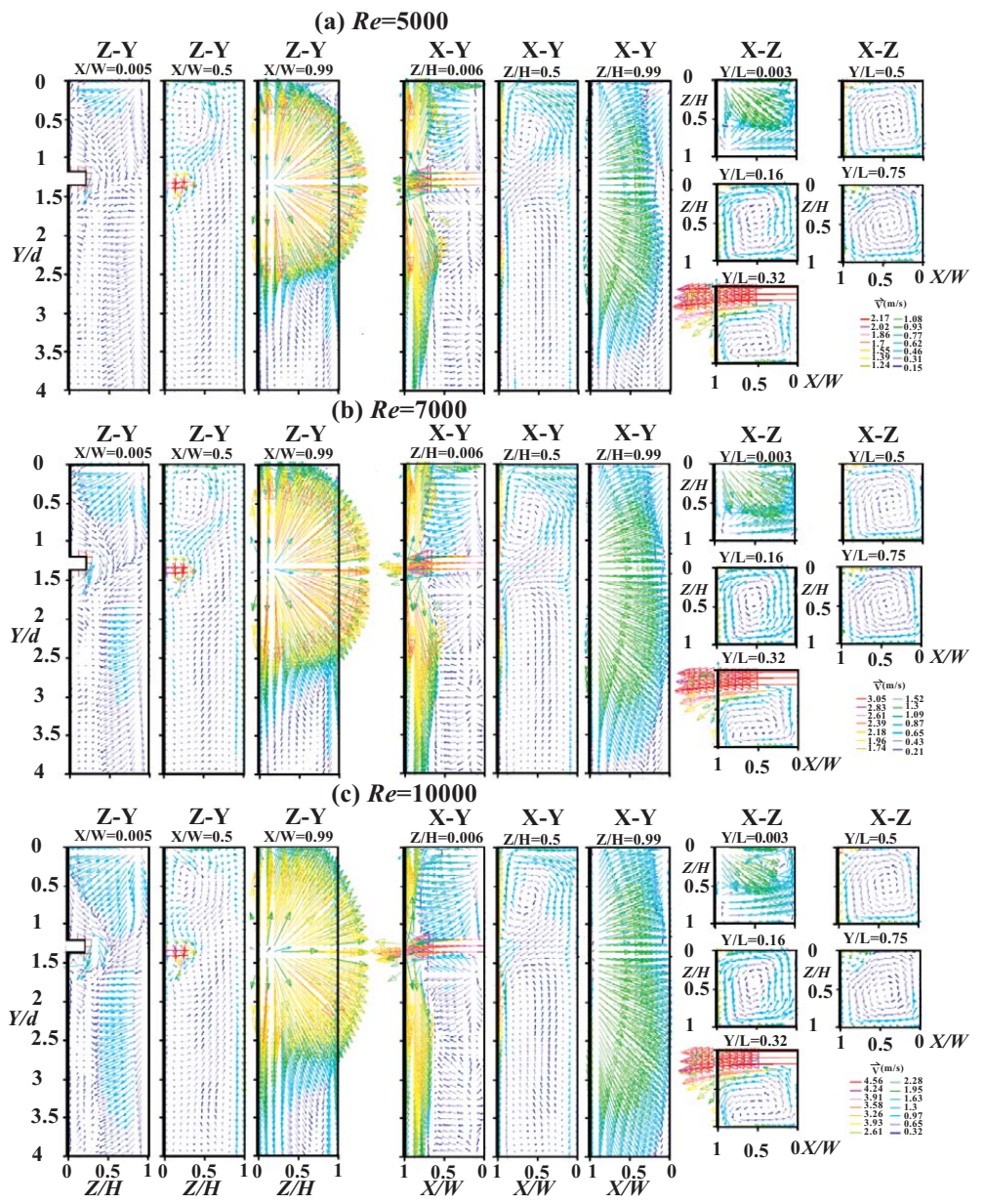

Fig. (4). Velocity vector plots over selected Z-Y, X-Y, X-Z planes at $R e=$ (a) 5000 (b) 7000 (c) 10000.

tices occur about $1 d$ under the blind wall as indicated by the circulating cell located on the upper left corner of the velocity vector plots on the $\mathrm{Z}-\mathrm{Y}$ plane at $\mathrm{X} / \mathrm{W}=0.5$ and on the $\mathrm{X}-\mathrm{Y}$ plane at $\mathrm{Z} / \mathrm{H}=0.5$, Fig. (4). Therefore the vortices induced by the upward flows underneath the blind wall are three dimensional and occupy the flow region above the jet plane adjacent to the jet wall. Near the side wall at $\mathrm{X} / \mathrm{W}=0$, the velocity vector plots on the $\mathrm{Z}-\mathrm{Y}$ plane at $\mathrm{X} / \mathrm{W}=0.005$ reveal the complex flow structures surrounding the lateral jet as a result of the jet-entrainment effect. Although the returned circulating flows are emanating from the upper right corner on the Z-Y plane at $\mathrm{X} / \mathrm{W}=0.005$, the flow circulation that envelopes the later jet creates a weak $\mathrm{Y}$-wise longitudinal roller cell alongside the $\mathrm{Z}=0$ axis under the jet plane. This $\mathrm{Y}$-wise longitudinal roller cell can be featured by viewing the flow velocity vector plots on a $\mathrm{Z}$-Y plane at $\mathrm{X} / \mathrm{W}=0.005$ adjacent to $\mathrm{Z}=0$ axis and on the $\mathrm{X}-\mathrm{Y}$ plane at $\mathrm{Z} / \mathrm{H}=0.006$ alongside the axis of $X=0$, Fig. (4). Another stronger coherent countercirculating $Y$-wise longitudinal roller cell is observed on the $Z$-Y plane at $X / W=0.005$ alongside $Z=1$. Near this back wall (X-Y plane at $Z=1$ ), the trajectories of the velocity vectors seen on the $\mathrm{X}-\mathrm{Y}$ plane at $\mathrm{Z} / \mathrm{H}=0.99$ reveal the directions of the return near-wall flows. As the $\mathrm{Y}$ loci approach toward the close $(\mathrm{Y}=0)$ and open $(\mathrm{Y} / \mathrm{L}=1)$ ends, the directions of the near-wall flows over the back wall are gradually skewed toward the upper and lower left corners respectively on the $\mathrm{X}-\mathrm{Y}$ plane at $\mathrm{Z} / \mathrm{H}=0.99$, Fig. (4). Along the $\mathrm{X} / \mathrm{W}=1$ axis on the $\mathrm{X}-\mathrm{Y}$ plane at $\mathrm{Z} / \mathrm{H}=0.99$, two short longitudinal $\mathrm{Y}$-wise vortical cells are respectively developed near the open and blind ends. The combined mechanisms triggered by the jet entrainment and impingement, the upward and downward redirected flows and the sectional swirls induced by the tangential lateral jet create the aforementioned complex flow structures, which involve three dimensional vortices and $\mathrm{Y}$ wise longitudinal roller cells, to characterize the turbulence structures and heat transfer performances.

The Reynolds stresses and turbulent scalar fluxes in the present $k$ - $\omega$ turbulence model are directly linked to the local velocity gradients of the mean flow by Equations (6) and (7) through the turbulent viscosity and diffusivity. The complex vortical flow structures in the present blind duct generate shear layers to affect the local velocity gradients of mean flow and therefore the distributions of turbulent kinetic energy $(k)$. The characteristic patterns of $k$ distributions over the sectional planes selected by Fig. (3) are depicted in Fig. (5) at $\mathrm{Re}=$ (a) 5000 (b) 7000 (c) 10000 . The cross examination of the fluid velocity plots in Fig. (4) and the $k$ counterparts in Fig. (5) clearly indicates that the high $k$ regions on each selected sectional plane develop at the locations where 
the large velocity gradients are generated either by the differential flow velocities or the different flow directions. In this regard, the lateral jet, the upward and downward flows resulting from wall impingement and the enveloping entrained flows over the outer edge of the lateral jet possess higher $k$ values on the various $\mathrm{X}-\mathrm{Y}$ and $\mathrm{Z}-\mathrm{Y}$ planes, Fig. (5). Underneath the blind wall at $\mathrm{Y} / \mathrm{L}=0.003$, the $k$ levels are considerably suppressed from those generated on its downstream X-Z planes, Fig. (5). Unlike the large cellar vortice observed on the $\mathrm{X}-\mathrm{Z}$ planes at $0.16,0.32,0.5,0.75 \mathrm{Y} / \mathrm{L}$, the velocity vector plots for the $\mathrm{X}-\mathrm{Z}$ plane at $0.003 \mathrm{Y} / \mathrm{L}$ in Fig. (4) indicate two strong emanating streams from the upper and lower left corners toward the duct core. The turbulence productions among these two emanating streams over the X$\mathrm{Z}$ plane at $0.003 \mathrm{Y} / \mathrm{L}$ are less than those generated by the large cellar vortice developed on its downstream X-Z planes. Nevertheless, the locations of the two high $k$ regions over the $\mathrm{X}-\mathrm{Z}$ plane at $0.003 \mathrm{Y} / \mathrm{L}$ showed by Figs. $\mathbf{5}(\mathbf{b})$ and $\mathbf{5}(\mathbf{c})$ correspond to the regions covering the two emanating streams depicted by Fig. (4). The characteristic patterns of the $k$ distributions over the various $\mathrm{X}-\mathrm{Y}, \mathrm{X}-\mathrm{Z}$ and $\mathrm{Z}-\mathrm{Y}$ planes seen in
Fig. (5) are generally followed by the simulation results obtained at $R e=5000,7000$ and 10000 . Nevertheless, the detailed vortical structures underneath the blind wall on the $\mathrm{X}$ Z plane at $0.003 \mathrm{Y} / \mathrm{L}$ as shown by Fig. (4) are systematically varied as $R e$ increases from 5000 to 10000 . The distributing $k$ pattern over the $\mathrm{X}-\mathrm{Z}$ plane at $0.003 \mathrm{Y} / \mathrm{L}$ showed by Fig. (5) is accordingly varied. Such $R e$-driven impact on the $k$ distribution over the $X-Z$ planes fade quickly in the downstream direction, leading to similar $k$ distributions on the $X-Z$ planes at $0.16,0.32,0.5,0.75 \mathrm{Y} / \mathrm{L}$ between three different $R e$ tested. It is also noticed that the variations of $G r_{g}$ at each fixed $R e$ do not incur the noticeable effects on the distribution of $v$ and $k$ but elevate their local values as $G r_{g}$ increases, leading to the consequential impact of $G r_{g}$ on heat transfer performances.

The heat transfer results obtained at $R e=5000$ and 10000 over the side, impinging, jet, back and blind walls are respectively collected in Figs. 6(a) and 5(b) where the three sets of $N u$ distributions over all the constituent duct walls with three ascending $G r_{g}$ are compared at fixed $R e$. The

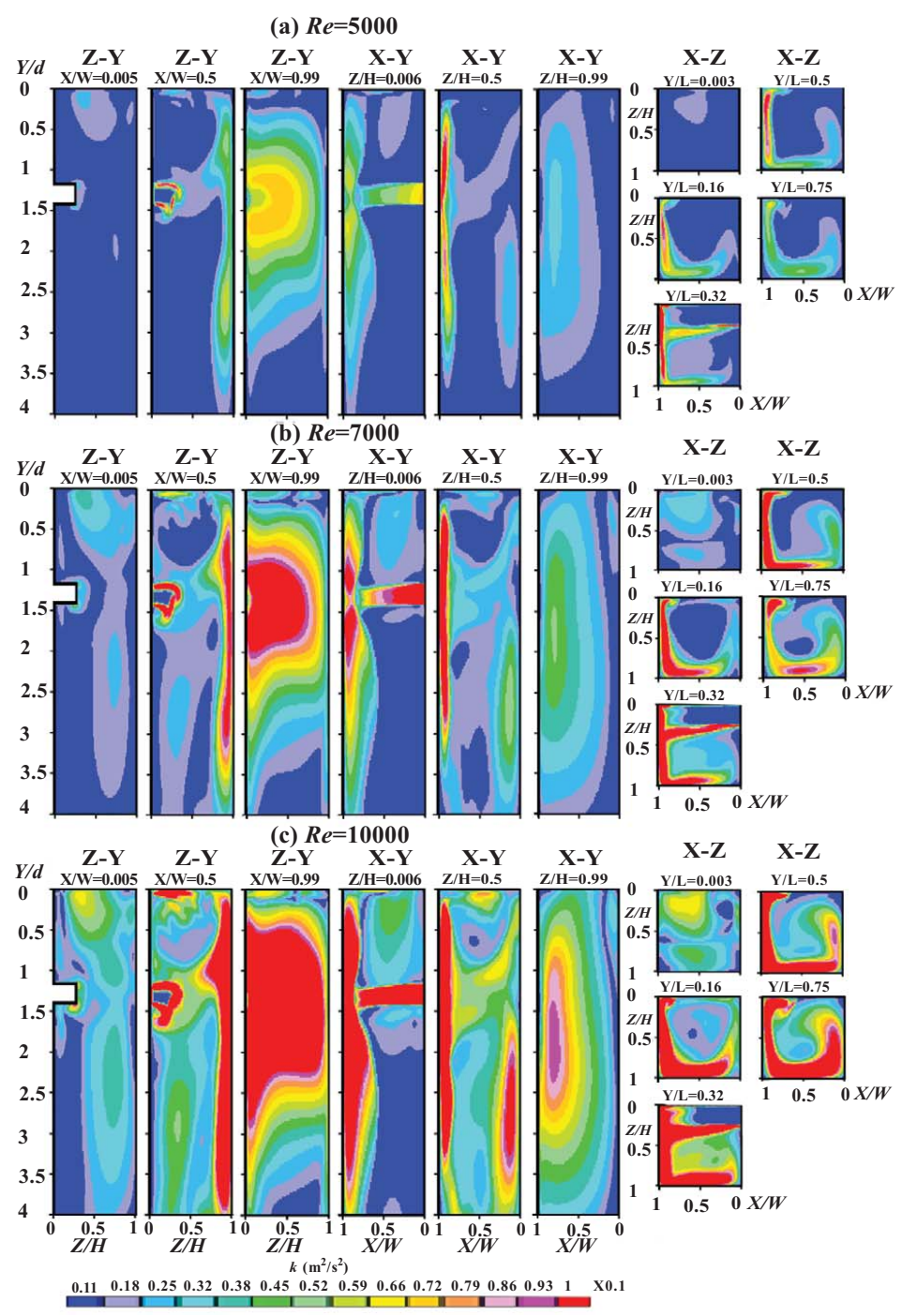

Fig. (5). Distributions of turbulent kinetic energy (k) over selected Z-Y, X-Y, X-Z planes at Re = (a) 5000 (b) 7000 (c) 10000. 

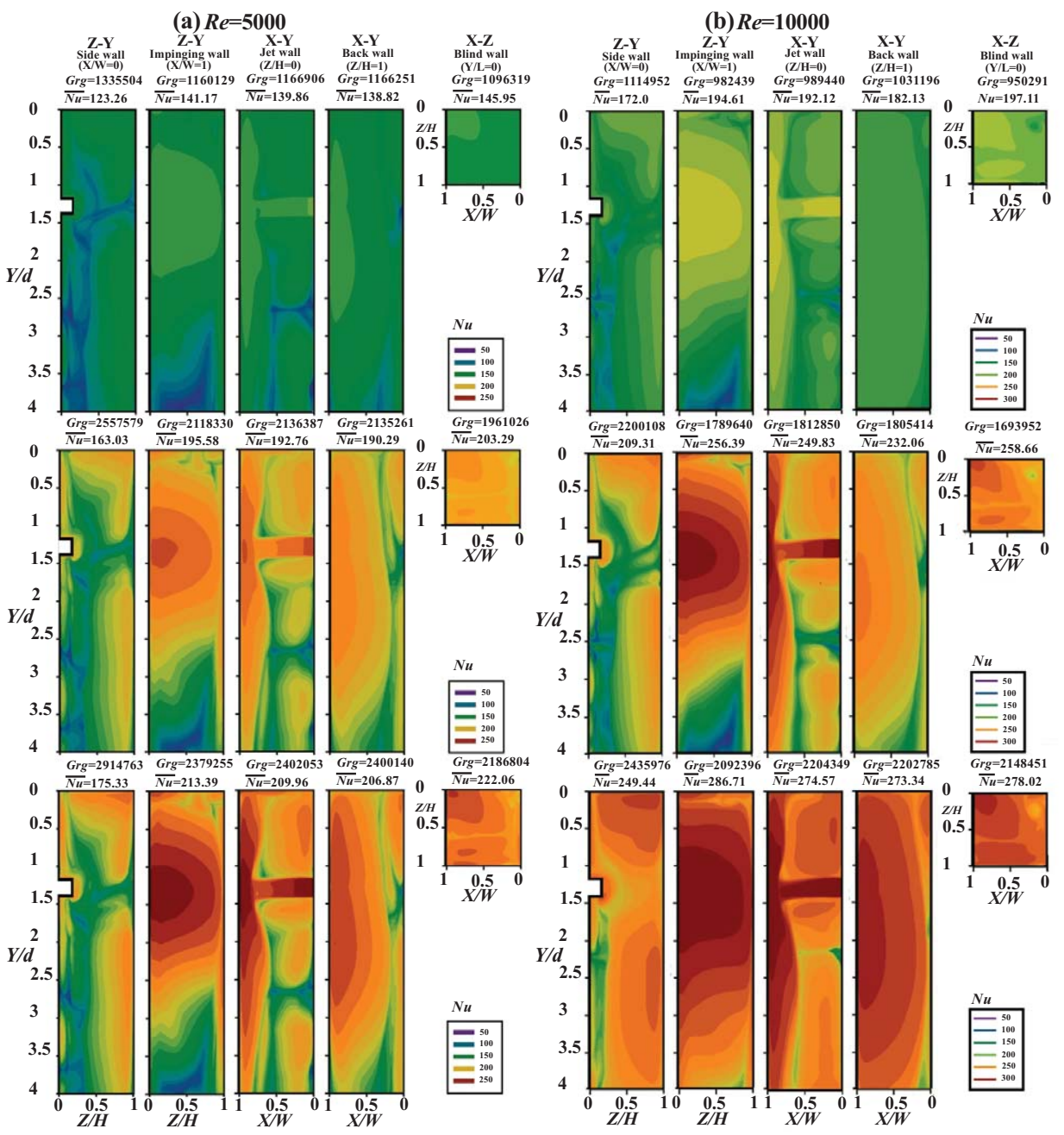

Fig. (6). $N u$ distributions over side wall, impinging wall, jet wall, back wall and blind wall at $R e=$ (a) 5000 (b) 10000 with three ascending buoyancy levels.

distribution of $N u$ over these constituent duct walls match closely with the near-wall $k$ distributions depicted by Fig. (5). The high $N u$ imprints on the constituent duct walls seen in Fig. (6) correspond well with the high $k$ regions on the near-wall Z-Y, X-Y and X-Z planes as shown in Fig. (5). The comparative heat transfer performances between these five constituent walls in terms of the area averaged Nusselt numbers $(\overline{\mathrm{Nu}})$ consistently follow the order of blind wall $>$ impinging wall $>$ jet wall $>$ back wall $>$ side wall. As shown by the $\mathrm{X}-\mathrm{Z}$ sectional $\vec{v}$ plots at $\mathrm{Y} / \mathrm{L}=0.003$ in Fig. (4), the strong stream emanating from the corner at $\mathrm{Z} / \mathrm{H}=0$ and $\mathrm{X} / \mathrm{W}=1$ sweeps over this sectional plane to generate the high $N u$ on the blind wall. On the impinging wall, the $N u$ distributions generally follow the typical heat transfer variations of an impinging jet with the radial $N u$ decays from the stagnation point at which the local $N u$ peak is generated. As the lateral entry jet attaches to the jet wall, the high $N u$ imprints on this jet wall follow the trajectories of the jet flows prior to and after the jet impingement. A lateral high $N u$ band along the pathway of the attached entry jet along with the $\mathrm{Y}$-wise high $N u$ profile alongside the $\mathrm{X} / \mathrm{W}=1$ axis, which reflects the contours of the upward and downward flows, are clearly visible on the jet wall, Fig. (6). On the sidewall from which the lateral entry jet is ejected, an enveloping high $N u$ ring surrounds the jet due to the high turbulent activities induced by the shear layers. The high $N u$ loops adjacent the blind end are also observed on the side wall as a result of the augmented turbulent activities, Fig. (5). As the sweeping nearwall flow induced by the swirls over the back wall is directed from the axis of $\mathrm{X} / \mathrm{W}=1$ toward the edge of $\mathrm{X} / \mathrm{W}=0$, the corresponding $\mathrm{X}$-wise $\mathrm{Nu}$ decays from $\mathrm{X} / \mathrm{W}=1$ toward $\mathrm{X} / \mathrm{W}=0$ prevail over the entire back wall. Although the increase of $R e$ elevates the local $N u$ values and amplifies the $N u$ gradients developed on each constituent duct wall, the characteristic patterns of the $\mathrm{Nu}$ distributions over these constituent duct walls are retained at all Re numbers tested. With regard to the impact of $G r_{g}$ on the heat transfer properties, 
the increase of $G r_{g}$ elevates the local $N u$ values at each tested $R e$; while the distribution of $N u$ still remain similar for all the $G r_{g}$ examined, Fig. (6). Therefore, the complex flow structures developed in the present blind duct with a lateral tangent jet issuing from the $0.32 \mathrm{Y} / \mathrm{L}$ plane are not modified by varying $R e$ and/or $G r_{g}$.

To examine the performances of heat transfer enhancement (HTE) using the present flow configuration, the variations of $\overline{N u}$ and $\overline{N u} / N u_{\infty}$ against $R e$ with three $G r_{g}$ levels for (a) side (b) impinging (c) jet (d) back (e) blind walls are depicted by Fig. (7). While the $\overline{N u}$ increases as $R e$ increases at each buoyancy level simulated, the increase of $G r_{g}$ at each tested Re elevates $\overline{N u}$. This reconfirms that the isolated buoyancy effect improves the heat transfer performance for each constituent duct wall. With $G r_{g}$ in the range of 9502912914763, there are about $45-50 \% \overline{N u}$ elevations for this blind duct. By way of normalizing $\overline{N u}$ with the DittusBoelter $\left(N u_{\infty}\right)$ references at all $R e$ and $G r_{g}$ examined, the HTE ratio evaluated as $\overline{N u} / N u_{\infty}$ for each constituent duct wall quantifies the degree of heat transfer elevation from the smooth pipe through-flow reference. As depicted by Fig. (7),

the $\overline{N u} / N u_{\infty}$ obtained at each buoyancy level for each constituent duct wall decreases with the increase of $R e$, which follows the general $\overline{N u} / N u_{\infty}$ versus $R e$ trends obtained with the passive HTE devices. With the present $R e$ and $G r_{g}$ conditions simulated the ranoes of $\overline{N u} / N u_{\sim}$ for the iet hack im- pingement, side and end walls are respectively elevated to 35.7, 2.8-5.6, 3-5.8, 2.7-4.8 and 3.1-6.1 respectively. Justified by the high $\overline{N u} / N u_{\infty}$ ratios acquired for each constituent duct wall, the use of a lateral entry jet to induce the sectional swirls and improve the fluency of the convective flow in the blind duct is demonstrated as an effective HTE measure to improve the heat transfer performances in the blind ducts.

\section{CONCLUSIONS}

As a preliminary study prior to the detailed experimental investigation for the heat transfer performance in a blind duct for various cooling applications, this numerical study examines the flow and heat transfer characteristics for a short square blind duct $(\mathrm{L} / d=4)$ with a lateral entry jet using the STAR-CD commercial code. The flow and heat transfer results are obtained at $R e=5000,7000$ and 10000. At each tested $R e$, three ascending heat flux levels on all the constituent duct walls are imposed to explore the $G r_{g}$ effect on heat transfer performances. Due to the presence of the tangential lateral jet which attaches and impinges on the jet and impinging duct walls respectively, the complex vortical flow structures are induced in this blind duct to generate various heat transfer properties over these constituent duct walls. The cross-plane swirls induced by the tangent entry jet together with the jet flows prior to and after the impingement are the dominant flow physics which influence the flow structures generated in this blind duct. Over the flow region above the entry jet plane, the three dimensional vortices underneath the hlind wall are induced hv the un-surging spent (a) Side wall

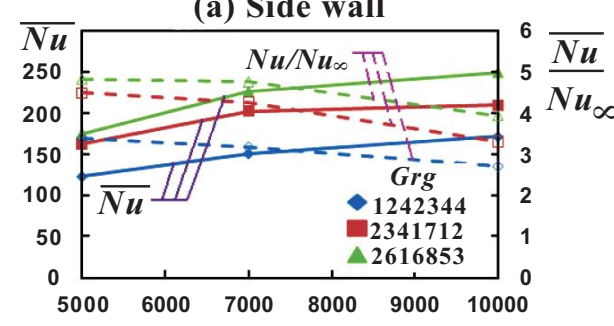

(b) Impinging wall

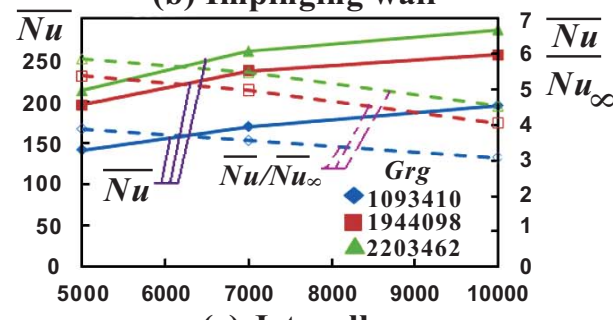

(c) Jet wall

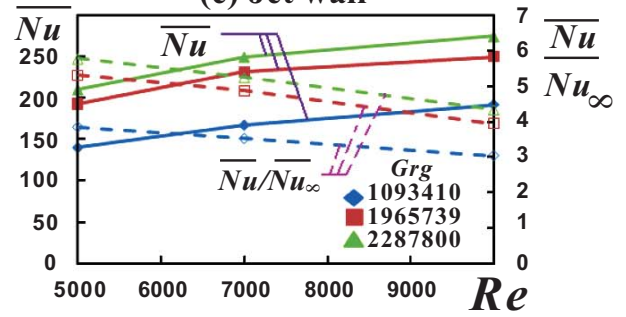

(d) Back wall

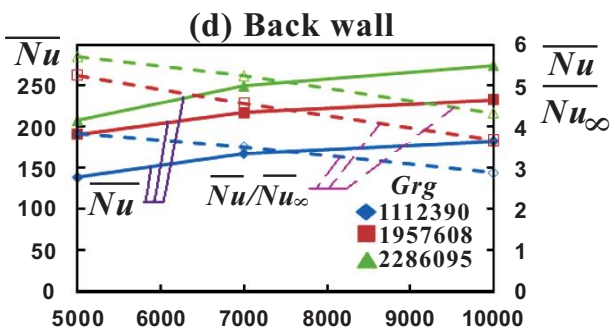

(e) Blind wall

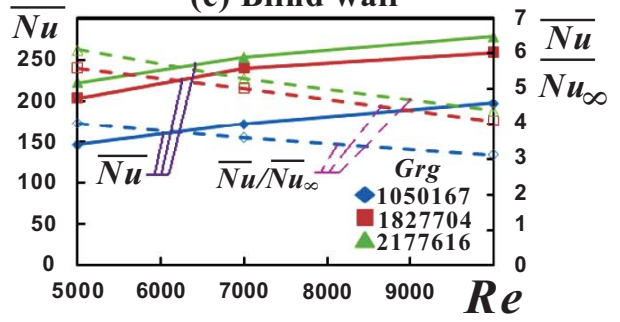

(1) 
jet-flow. The complex flow structures developed in the present blind duct generate shear layers to affect the local velocity gradients of mean flow and therefore the $k$ distributions. The high $k$ regions are generated at the locations where the large velocity gradients are produced. The various patterns of $\mathrm{Nu}$ over the five constituent duct walls match closely with the near-wall $k$ distributions, indicating the dominance of near-wall turbulent and flow characteristics on the wall-tofluid heat transfer properties. While the distributing $N u$ patterns over each constituent duct wall remain similar at different $R e$ and $G r_{g}$, the increase of $R e$ or/and $G r_{g}$ elevates local $N u$ value and therefore $\overline{N u}$. The varying manner of the HTE ratio in terms of $\overline{N u} / N u_{\infty}$ against $R e$ for the present blind duct follows the typical $\overline{N u} / N u_{\infty}$ versus $R e$ trends obtained from other passive HTE devices, which decreases as Re increases. Due to the augmented turbulent activities, the sectional vortical flows induced by the lateral tangent jet and the improved strength of the convective flow in the blind duct, the $\overline{N u} / N u_{\infty}$ over the jet, back, impingement, side and end walls are respectively elevated to $3-5.7,2.8-5.6,3-5.8,2.7$ 4.8 and 3.1-6.1 at the test conditions of $5000 \leq R e \leq 10000$ and $950291 \leq G r_{g} \leq 2914763$. Justified by these high $\overline{N u} / N u_{\infty}$ ratios, the use of a tangent entry jet appears as an effective HTE measure to improve the heat transfer performances in blind ducts.

\section{ACKNOWLEDGEMENT}

This research project was supported by National Science Council, Taiwan, under the grants NSC 96-2221-E-022$015 \mathrm{MY} 3$.

\section{NOMENCLATURE}

\section{English Symbols}

$$
\begin{array}{ll}
d & =\text { Hydraulic diameter of blind duct }(\mathrm{m}) \\
d_{j} & =\text { Jet diameter }(\mathrm{m}) \\
G r_{g} & =\text { Gravitational Grashof number }=\mathrm{g} \beta_{t h}\left(T_{w}-T_{j}\right) d \\
\mathrm{H} & =\text { Duct height }(\mathrm{m}) \\
k & =\text { Turbulent kinetic energy }=0.5\left(\overline{u_{i} u_{i}}\right) \\
k_{f} & =\text { Thermal conductivity of fluid }\left(\mathrm{Wm}^{-1} \mathrm{~K}^{-1}\right) \\
\mathrm{L} & =\text { Duct length (m) } \\
N u & =\text { Local endwall Nusselt number }=q \mathrm{D} / k_{f}\left(T_{w}-T_{j}\right) \\
\hline N u & =\text { Area area-averaged Nusselt number } \\
q & =\text { Convective heat flux }\left(\mathrm{Wm}^{-2}\right) \\
R e & =\text { Reynolds number }=\rho \mathrm{W}_{\mathrm{m}} d / \mu \\
R e_{j} & =\text { Jet Reynolds number }=\rho V_{j} d_{j} / \mu \\
S_{i, j} & =\text { Shear stress component }\left(\mathrm{Nm}^{-2}\right) \\
T_{j} & =\text { Jet entry temperature }(\mathrm{K}) \\
T_{w} & =\text { Local wall temperature }(\mathrm{K}) \\
\bar{U}_{i, j} & =\text { Time mean fluid velocity }\left(\mathrm{ms}^{-1}\right)
\end{array}
$$

$$
\begin{array}{ll}
u_{i, j} & =\text { Fluctuating fluid velocity }\left(\mathrm{ms}^{-1}\right) \\
V_{j} & =\text { Flow velocity at exit of jet nozzle }\left(\mathrm{ms}^{-1}\right) \\
\mathrm{W} & =\text { Duct width }(\mathrm{m}) \\
W_{m} & =\text { Mean flow velocity }\left(\mathrm{ms}^{-1}\right) \\
\mathrm{X}-\mathrm{Y}-\mathrm{Z} & =\text { Coordinates }(\mathrm{m})
\end{array}
$$

\section{Greek Symbols}

$\begin{array}{ll}\beta_{t h} & =\text { Thermal expansion coefficient of coolant }\left(\mathrm{K}^{-1}\right) \\ \varepsilon & =\text { Turbulent dissipation function }\left(\mathrm{m}^{2} \mathrm{~s}^{2}\right) \\ \rho & =\text { Density of fluid }\left(\mathrm{kgm}^{-3}\right) \\ \tau_{i, j} & =\text { Shear stress }\left(\mathrm{Nm}^{-2}\right) \\ \mu & =\text { Fluid dynamic viscosity }\left(\mathrm{kgm}^{-1} \mathrm{~s}^{-1}\right) \\ \mu_{t} & =\text { Turbulent viscosity }\left(\mathrm{kgm}^{-1} \mathrm{~s}^{-1}\right) \\ v & =\text { Kinematic viscosity of coolant }\left(\mathrm{m}^{2} \mathrm{~s}^{-1}\right) \\ \Omega_{i, j} & =\text { Mean vorticity tensor }\left(\mathrm{s}^{-1}\right) \\ \omega & =\text { Specific dissipation rate }=\rho k / \mu_{t}\left(\mathrm{~s}^{-1}\right)\end{array}$

\section{Subscripts}

$i, j \quad=$ Direction of tension notation

\section{REFERENCES}

[1] G.H.S. Lock, The Tubular Thermosyphon. Oxford Science Publications, Oxford University Press, England, pp. 286-296, 1992.

[2] A. Bejan, and C.L. Tien, "Fully developed natural counterflow in a long horizontal pipe with different end temperatures", Int. J. Heat Mass Transfer, vol. 21, pp. 701-708, 1978.

[3] O. Polat, and E. Bilgen, "Laminar natural convection in inclined open shallow cavities", Int. J. Thermal Sciences, vol. 41, pp. 360$368,2002$.

[4] Y.L. He, W.Q. Tao, and T.S. Zhao, "Steady natural convection in a tilted long cylindrical envelop with lateral adiabatic surface, Part 1: theoretical modeling and numerical treatments", Numeric. Heat Transfer A, vol. 44, pp. 375-397, 2003.

[5] Y.L. He, W.Q. Tao, T.S. Zhao, and Z.Q. Chen, "Steady natural convection in a tilted long cylindrical envelop with lateral adiabatic surface", Part 2: heat transfer rate, flow patterns and temperature distributions, Numeric. Heat Transfer A, vol. 44, pp. 399-431, 2003.

[6] E. Bilgen, and H. Oztop, "Natural convection heat transfer in partially open inclined square cavities", Int. J. Heat Mass Transfer, vol. 48, pp. 1470-1479, 2005.

[7] C.-C. Kao, "Experimental study of flow field and heat transfer in staggered ribbed channel with reciprocating motion", M.S. thesis, National Tsing Hua University, Taiwan, R.O.C., 2006 (in Chinese).

[8] S.W. Chang, L.M. Su, T.L. Yang, and S.F. Chiou, "Enhanced heat transfer of shaker-bored piston cooling channel with twisted plate", J. Heat Transfer Engineering, vol. 28, pp. 321-334, 2007.

[9] S.W. Chang, W.D. Morris, T.-M. Liou, and S.F. Chiou, "Heat transfer in a reciprocating thermosyphon fitted with staggered transverse ribs", AIAA J. Thermophys. Heat Transfer, vol. 21, pp. 568-581, 2007.

[10] T.L. Yang, and S.W. Chang, "Heat transfer in tilted reciprocating anti-gravity open thermosyphon", Int. J. Heat and Mass Transfer, vol. 52, pp. 880-893, 2009.

[11] S.W. Chang, and A. W. Lees, "Heat transfer of tilted reciprocating thermosyphon with jet entry flow", Int. J. Heat Mass Transfer, vol. 53, pp. 1380-1391, 2010.

[12] “STAR-CD Methodology", Version 3.26, Start CD Adapco Group, 2005.

[13] J.D. Jackson, M.A. Cotton, and B.P. Axcell, "Studies of mixed convection in vertical tubes", Int. J. Heat Fluid Flow, vol. 10, pp. $2-14,1989$ 
[14] W.S. Kim, S. He, and J.D. Jackson, "Assessment by comparison with DNS data of turbulence models used in simulations of mixed convection", Int. J. Heat Mass Transfer, vol. 51, pp. 1293-1312, 2008.

[15] M.A. Cotton, and J.D. Jackson, "Vertical tube air flows in the turbulent mixed convection regime calculated using a low-
Reynolds-number $k$ - $\varepsilon$ model", Int. J. Heat Mass Transfer, vol. 33, pp. 275-286, 1987.

[16] A.A. Steiner, "On the reverse transition of turbulent flow under the action of buoyancy forces", J. Fluids Mechan., vol. 47, pp. 71-75, 1971.

Received: September 23, 2010

Revised: December 14, 2010

Accepted: December 14, 2010

(C) Chang and Cai; Licensee Bentham Open.

This is an open access article licensed under the terms of the Creative Commons Attribution Non-Commercial License (http:/creativecommons.org/licenses/by-nc/ $3.0 /$ ) which permits unrestricted, non-commercial use, distribution and reproduction in any medium, provided the work is properly cited. 